Gut, 1974, 15, 608-613

\title{
A comparison of stool fluid and stool dialysate obtained in vivo
}

\author{
MICHAEL J. TARLOW AND HAZEL THOM
}

From the Department of Child Health, University of Aberdeen

SUMMARY Stool fluid has been obtained for analysis by homogenization and high speed centrifugation of fresh stool.

This fluid, from two healthy individuals with soft stools has been compared with stool dialysate obtained in vivo by retrieval of swallowed dialysis bags from their stools. Stool fluid was more acid, with a higher osmolality, an increased concentration of organic anions, sugar and ammonia, and a lower bicarbonate concentration than dialysate in vivo. It is suggested that in the individuals studied, dialysate in vivo may not be in equilibrium with the stool fluid surrounding it, and may not represent a true dialysate of faecal water.

The investigation of the composition of stool poses a number of difficult problems. Stool is a multiphasic system containing solid material, colloidal solutions of both sol and gel varieties and true crystalloid solutions. The solutes in true solution within the stool may be sequestered into two or more separate compartments.

Early techniques for the investigation of the composition of stool involved acid digestion or ashing, with subsequent chemical analysis. These techniques are obviously of limited applicability, they do not differentiate between material in solid or liquid phases of stool, and can only be applied to minerals resistant to these drastic physical or chemical techniques.

In 1961, an elegant technique for dialysis in vivo of stool was introduced by Wrong and his coworkers (Wrong, Morrison, and Hurst, 1961). This involved subjects swallowing bags made of cellulose acetate dialysis tubing, closed at both ends and containing a small amount of an oncotic agent. These bags were recovered from the stool, and it was assumed that the contents represented 'the extracellular component of faecal water'.

Stool can be separated by high speed centrifugation into a clear, supernatant fluid and a residual 'pellet'. The supernatant can be analysed by conventional chemical techniques, and this paper compares the composition of a faecal dialysate obtained in vivo by the method of Wrong et al (1961) with that of stool fluid obtained directly by centrifugation.

Received for publication 23 April 1974.

\section{Methods}

Stools were collected from two healthy adult volunteers who produced rather soft stools, since it was found that hard stool could not be separated into solid and liquid components by centrifugation. Dialysis bags, prepared by the method of Wrong et al (1965), were swallowed and later collected from the stools. Both stool and dialysate were immediately analysed or deep frozen.

Stool weights varied between $106 \mathrm{~g}$ and $245 \mathrm{~g}$ (mean $163 \mathrm{~g}$ ) and transit times were $24-36$ hours in both volunteers.

To obtain stool fluid, the stool (after thawing if frozen) was homogenized and centrifuged at $40000 \mathrm{~g}$ for 30 minutes at $0^{\circ} \mathrm{C}$. The supernatant was then decanted.

Sodium and potassium concentrations were measured by flame photometry; chloride by the method of Schales and Schales (1941); ammonia by the Conway microdiffusion technique (Conway, 1957); bicarbonate by the manometric method of Van Slyke and Neill (1924); organic anions by a modification of the method of Van Slyke and Palmer (1920) using a pH meter and microelectrode; total sugar by a modification of the copper reduction technique described by Somogyi (1952); individual sugars by semiquantitative thin-layer chromatography on silica gel (Baron and Economidis, 1963); total stool water by drying a homogenized aliquot to constant weight at $100^{\circ} \mathrm{C}$; and osmolality by freezing-point depression using an Advanced osmometer. 
The water content of four samples of stool fluid was estimated by drying to constant weight on a boiling waterbath. A mean water content of 0.93 $\mathrm{g} / \mathrm{ml}$ was found. Since this was very similar to the mean water content of 'Wrong' in vivo dialysates using dextran as the oncotic agent $(0.89 \mathrm{~g} / \mathrm{ml}$, Wrong et al, 1965), no correction factor was applied when comparing the two fluids.

\section{Results}

Table I shows the composition of the dialysates, in vivo and of the stool fluid in the stool surrounding them. Although the average composition of the dialysate in vivo lies within 1 SD of the mean for the dialysates studied by Wrong et al (1965), except for slightly more acid $\mathrm{pH}$, the composition of stool fluid is different. The dialysate has a higher $\mathrm{pH}$, lower osmolality, and lower concentrations of sugar, organic anions (mainly short-chain fatty acids), sodium, and ammonia, and a higher concentration of bicarbonate than the surrounding stool fluid.

The figure shows a thin-layer chromatogram of sugars from stool fluid compared with dialysate in vivo from the same stool. This confirms the difference in sugar concentrations of the two fluids shown in table I.

\section{EFFECTS OF PROCESSING ON STOOL FLUID COMPOSITION}

\section{Freezing and thawing}

A freshly passed stool was mixed with a spatula and divided into two roughly equal portions. One half was immediately deep frozen then thawed and analysed 24 hours later, whereas the second half was

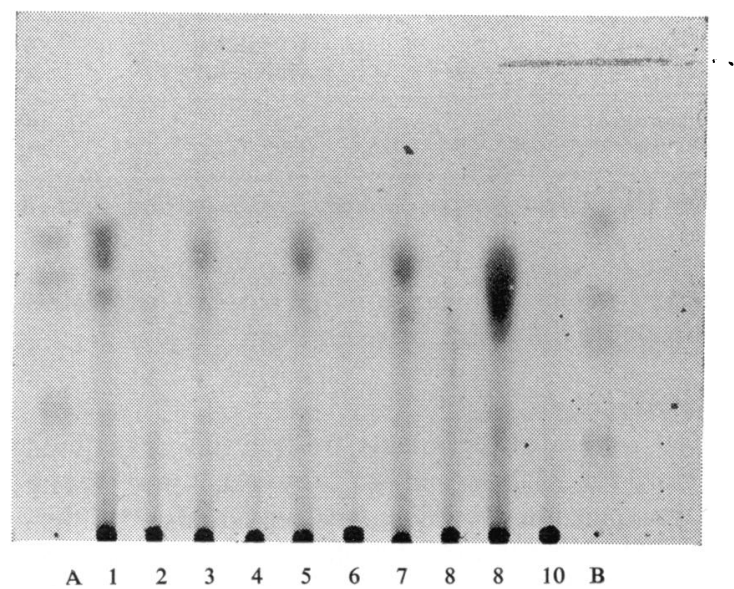

Fig Thin-layer chromatography of sugars from stool fluid and corresponding stool dialysates in vivo. Odd numbered samples are of stool fluid and the following even numbered samples of corresponding dialysates in vivo. Standard sugar solutions $A$ and $B$ are at the ends of the plate. Reading from the origin, standard $A$ contains lactose, galactose, and glucose, and standard $B$, lactulose, sucrose, fructose, and ribose.

analysed immediately. As can be seen (table II), there were only minor differences in composition between the two halves of the stool.

\section{Homogenization}

A fresh stool was mixed with a spatula and divided into two portions; one was homogenized and centrifuged, the other centrifuged directly, without homogenization. Table III demonstrates the results of

\begin{tabular}{|c|c|c|c|c|}
\hline & Stool Fluid & In-vivo Stool Dialysate & $n$ & $\boldsymbol{p}$ \\
\hline $\begin{array}{l}\text { pH } \\
\text { Osmolality (mOsm/kg) } \\
\text { Organic anions (m-equiv/1) } \\
\text { Total sugar (mg/100 ml) } \\
\text { Sodium (m-equiv/1) } \\
\text { Potassium (m-equiv/1) } \\
\text { Chloride (m-equiv/1) } \\
\text { Ammonia (m-equiv/1) } \\
\text { Bicarbonate (m-equiv/1) }\end{array}$ & $\begin{array}{l}6 \cdot 1 \pm 0 \cdot 7 \\
475 \pm 66 \\
203 \pm 27 \\
542 \pm 246 \\
32 \pm 19 \\
70 \pm 33 \\
23 \pm 8 \\
33 \text { (range } 22 \cdot 5-55 \text { ) } \\
7 \cdot 3 \text { (range } 0 \cdot 9-27 \text { ) }\end{array}$ & $\begin{aligned} & 6.4 \pm 0.8 \\
& 361 \pm 56 \\
& 158 \pm 30 \\
& 249 \pm 124 \\
& 23 \pm 15 \\
& 68 \pm 34 \\
& 22 \pm 9 \\
&17 \text { (range } 6 \cdot 1-27 \cdot 7) \\
&20.5 \text { (range } 3 \cdot 5-64)\end{aligned}$ & $\begin{array}{r}14 \\
14 \\
14 \\
13 \\
14 \\
14 \\
14 \\
9 \\
7\end{array}$ & $\begin{array}{l}<0.05 \\
<0.001 \\
<0.001 \\
<0.02 \\
<0.02 \\
\mathrm{~ns}^{1} \\
\mathrm{~ns}^{1} \\
<0.001 \\
<0.005\end{array}$ \\
\hline
\end{tabular}

Table I The composition of stool fluid and in-vivo stool dialysate

${ }^{1}$ ns $=$ not significant

\begin{tabular}{|c|c|c|c|c|c|c|c|}
\hline Stool & $p H$ & Osmolality (mOsm/kg) & Organic Anions (m-equiv/1) & $\begin{array}{l}\text { Total Sugar } \\
(m g \%)\end{array}$ & $\begin{array}{l}\mathrm{Na}^{+} \\
(m-e q u i v / l)\end{array}$ & $\begin{array}{l}K^{+} \\
(m-e q u i v / l)\end{array}$ & $\underset{(m-e q u i v / l)}{\mathrm{Cl}^{-}}$ \\
\hline $\begin{array}{l}\text { Analysed immediately } \\
\text { Frozen for } 24 \mathrm{hr} \text { and thawed }\end{array}$ & $\begin{array}{l}5.9 \\
6.0\end{array}$ & $\begin{array}{l}472 \\
475\end{array}$ & $\begin{array}{l}194 \\
190\end{array}$ & $\begin{array}{l}245 \\
200\end{array}$ & $\begin{array}{l}23 \\
29\end{array}$ & $\begin{array}{l}102 \\
109\end{array}$ & $\begin{array}{l}16 \\
17\end{array}$ \\
\hline
\end{tabular}

Table II Effect of freezing and thawing on stool fluid composition 


\begin{tabular}{|c|c|c|c|c|c|}
\hline & $p H$ & $\begin{array}{l}\text { Osmolality } \\
(\mathrm{mOsm} / \mathrm{kg})\end{array}$ & $\begin{array}{l}\text { Organic Anions } \\
(m \text {-equiv } / I)\end{array}$ & $\begin{array}{l}\mathrm{HCO}_{8}^{-} \\
\text {(m-equiv/l) }\end{array}$ & $\begin{array}{l}\mathrm{NH}_{4}^{+} \\
\text {(m-equiv/l) }\end{array}$ \\
\hline $\begin{array}{l}\text { Homogenized stool } \\
\text { Unhomozenized stool }\end{array}$ & $\begin{array}{l}6 \cdot 4 \\
6 \cdot 4\end{array}$ & $\begin{array}{l}420 \\
420\end{array}$ & $\begin{array}{l}192 \\
195\end{array}$ & $\begin{array}{l}8 \cdot 7 \\
9 \cdot 4\end{array}$ & $\begin{array}{l}27 \cdot 8 \\
25 \cdot 4\end{array}$ \\
\hline
\end{tabular}

Table III Effect of stool homogenization on stool fuid composition

analysis of the two portions of stool. There is no appreciable difference between them.

\section{In-vitro dialysis}

In four separate experiments, fresh stool was dialysed in vitro for 24 hours at $4^{\circ} \mathrm{C}$, by placing a Wrong dialysis bag into it. There was no significant difference between the pH, osmolality, and sodium and potassium concentrations of the stool fluid and the in-vitro dialysate. The organic anion concentration, however, was significantly $(16 \%)$ higher in the stool fluid.

\section{Delay in analysis}

Another fresh stool was mixed and divided into two; stool fluid from one half was analysed immediately, the other half was placed in a refrigerator at $4^{\circ} \mathrm{C}$ for 24 hours and then homogenized, centrifuged, and analysed. It can be seen from table IV that trivial, if any, fermentation had occurred in the refrigerated sample.

\section{Stool sterilization and stool composition}

Immediately on voiding, a fresh stool was divided in two and one half mixed with $10 \mathrm{ml} 10 \%$ neutral formalin. Both halves were then analysed in the usual way. The results are shown in table V. The increased osmolality is due to the presence of formaldehyde molecules, and the lowered ammonia concentration to the formation of the condensation product tetramethylenediamine when ammonia and

\begin{tabular}{llll}
\hline & $\begin{array}{lll}p H \\
\text { Osmolality } \\
(\mathrm{mOsm} / \mathrm{kg})\end{array}$ & $\begin{array}{l}\text { Organic Anions } \\
(\text { m-equiv/l) }\end{array}$ & $\begin{array}{l}\mathrm{NH}_{\mathbf{4}}^{+} \\
(\text {m-equiv/l) }\end{array}$ \\
\hline $\begin{array}{l}\text { Analysed immediately } \\
\begin{array}{l}\text { Analysed after } 24 \mathrm{hr} \\
\text { at } 4^{\circ} \mathrm{C}\end{array}\end{array}$ & 440 & 184 & 24.9 \\
\hline
\end{tabular}

Table IV Effect of delayed analysis on stool fluid composition formaldehyde are mixed. There is, however, no suggestion that our practice of analysis without prior stool sterilization has led to any increase in organic anion or sugar in the stool.

\section{Sequestration of stool water}

A fresh stool was homogenized, and a $10 \mathrm{~g}$ aliquot dried to constant weight to find the total stool water. The remainder of the stool was centrifuged, and supernatant and stool 'pellet' were separated. The 'pellet' was rehomogenized with a measured amount of water and recentrifuged. The second supernatant, derived from the stool pellet, was analysed at the same time as the initial supernatant; from this the solute composition of the original pellet was calculated on the assumption that all the pellet fluid was available for dilution. The composition of 'supernatant' and 'pellet' fluids is shown in table VI. Had some of the stool fluid in the pellet been sequestered, and incapable of mixing with the added water, the pellet fluid as analysed would have appeared more dilute than the supernatant. Since (within the limits of experimental error) both have the same composition, there is no evidence of an appreciable compartment

\begin{tabular}{lcc}
\hline & $\begin{array}{l}\text { Supernatant Fluid } \\
\text { (original supernatant) }\end{array}$ & $\begin{array}{l}\text { 'Pellet' Fluid (extracted } \\
\text { from original 'pellet') }\end{array}$ \\
\hline $\begin{array}{l}\text { pH } \\
\begin{array}{l}\text { Osmolality } \\
\text { (mOsm/kg) }\end{array}\end{array}$ & 5.65 & 5.65 \\
$\begin{array}{l}\text { Organic Anions } \\
\text { (m-equiv/l) }\end{array}$ & 437 & 430 \\
$\begin{array}{l}\mathrm{Na}^{+} \\
(\mathrm{m}-\text {-equiv/l) }\end{array}$ & 207 & 191 \\
$\begin{array}{l}\mathrm{K}^{+} \\
\text {(m-equiv/l) }\end{array}$ & 54 & 51 \\
$\begin{array}{l}\text { NH+ } \\
\text { (m-equiv/l) }\end{array}$ & 92 & 87 \\
$\begin{array}{l}\mathrm{Cl}^{-} \\
\text {(m-equiv/l) }\end{array}$ & 21 & 19 \\
\hline
\end{tabular}

Table VI Comparative composition of the fluid in stool supernatant and in 'pellet' remaining after centrifugation.

\begin{tabular}{|c|c|c|c|c|c|c|c|c|}
\hline & $p H$ & $\begin{array}{l}\text { Osmolality } \\
(\mathrm{mOsm} / \mathrm{kg})\end{array}$ & $\begin{array}{l}\text { Organic Anions } \\
\text { (m-equiv/l) }\end{array}$ & $\begin{array}{l}\text { Total Sugar } \\
(\mathrm{mg} \%)\end{array}$ & $\begin{array}{l}\mathrm{Na}^{+} \\
\text {(m-equiv/l) }\end{array}$ & $\begin{array}{l}K^{+} \\
(m-e q u i v / l)\end{array}$ & $\begin{array}{l}\mathrm{Cl}^{-} \\
\text {(m-equiv/l) }\end{array}$ & $\begin{array}{l}\mathrm{NH}^{+} \\
\text {(m-equiv/l) }\end{array}$ \\
\hline $\begin{array}{l}\text { No preservative } \\
10 \mathrm{ml} 10 \% \text { Formalin }\end{array}$ & $\begin{array}{l}6.0 \\
5.7\end{array}$ & $\begin{array}{l}380 \\
558\end{array}$ & $\begin{array}{l}152 \\
167\end{array}$ & $\begin{array}{l}160 \\
130\end{array}$ & $\begin{array}{l}23 \\
23\end{array}$ & $\begin{array}{l}87 \\
87\end{array}$ & $\begin{array}{l}14 \\
14\end{array}$ & $\begin{array}{l}25 \\
16\end{array}$ \\
\hline
\end{tabular}

Table V Effect of formalin on stool fluid composition 


\begin{tabular}{|c|c|c|c|c|c|c|c|c|}
\hline & $p H$ & $\begin{array}{l}\text { Osmolality } \\
(m O s m / k g)\end{array}$ & $\begin{array}{l}\text { Organic Anion } \\
\text { Concentration } \\
\text { (m-equiv/l) }\end{array}$ & $\begin{array}{l}\text { Total Sugar } \\
(m g \%)\end{array}$ & $\begin{array}{l}\mathrm{Na}^{+} \\
(\mathrm{m} \text {-equiv/l) }\end{array}$ & $\begin{array}{l}K^{+} \\
(m-e q u i v / l)\end{array}$ & $\begin{array}{l}\mathrm{Cl}^{-} \\
(\mathrm{m} \text {-equiv } / l)\end{array}$ & $\begin{array}{l}\mathrm{NH}_{\mathrm{c}}{ }^{+} \\
(\mathrm{m} \text {-equiv/l) }\end{array}$ \\
\hline
\end{tabular}

Table VII Composition of fluid in different dialysis bags from the same stool compared with that of stool fluid from that stool

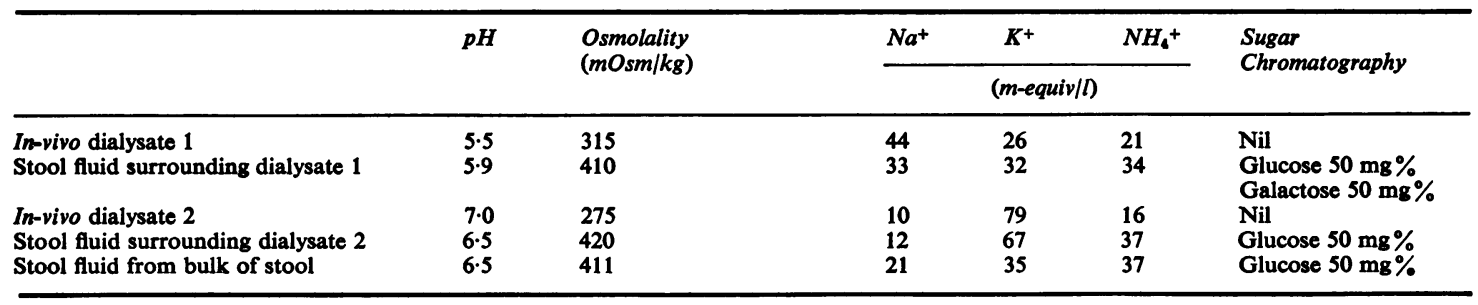

Table VIII Composition of dialysate in vivo compared with that of surrounding stool fluid

\begin{tabular}{llllll}
\hline Stool Fluid & $p H$ & $\begin{array}{l}\text { Osmolality } \\
(\mathrm{mOsm} / \mathrm{kg})\end{array}$ & $\begin{array}{l}\text { Organic Anions } \\
(\mathrm{m} \text {-equiv/l) }\end{array}$ & $\begin{array}{l}\text { Ammonia } \\
(\mathrm{m} \text {-equiv/l) }\end{array}$ & $\begin{array}{l}\text { Total Sugar } \\
(\mathrm{mg} / 100 \mathrm{ml})\end{array}$ \\
\hline Initially & 5.6 & 455 & 199 & 30 & 200 \\
After $24 \mathrm{hr}$ incubation at $37^{\circ} \mathrm{C}$ & 4.9 & 608 & 307 & 62 & 340 \\
\hline
\end{tabular}

Table IX Effect of incubation in vitro of stool on the composition of stool fluid

of sequestered stool fluid within the pellet and for the purposes of this study all the fluid in the stool may be assumed to be of similar composition.

\section{Composition of different dialysis bags from the same stool}

Several dialysis bags were swallowed simultaneously and recovered from different parts of the same stool. Table VII demonstrates the composition of the dialysis fluid from each bag and the composition of the stool fluid. Table VIII shows the results of a similar experiment in which the contents of each of two dialysis bags were analysed together with stool fluid from the 10-15 $\mathrm{g}$ of stool immediately surrounding each bag.

In-vitro incubation of stool

Stool was incubated anaerobically in a plastic bag at $37^{\circ} \mathrm{C}$ for 24 hours. Table IX demonstrates an increase in stool sugar and ammonia concentrations following incubation.

\section{Discussion}

It is apparent from table I that in vivo dialysate and stool fluid are of different composition. This difference might be real or might be an artefact due to chemical changes in the stool after collection. The technique used in the preparation of stool fluid involved three basic procedures: freezing and thawing, homogenization, and high-speed centrifugation. Tables I and III show that freezing and thawing and homogenization affect stool fluid composition only slightly, if at all, and cannot account for the marked difference in composition between stool fluid and dialysate in vivo.

In vitro dialysis of stool yields fluid of essentially similar composition to that obtained by centrifugation, thus excluding the possibility that stool fluid is artificially altered by rupture of bacterial cells and debris in the process of centrifugation. To account for the differing composition of dialysate and stool fluid by contamination of the latter with bacterial 
protoplasm, stool bacteria would need to have a much higher intracellular osmolality and fatty acid content and lower potassium content than have been demonstrated for $E$. coli (Law, 1961 ; Cirillo, 1966).

Although there was no significant difference in $\mathrm{pH}$, sodium and potassium concentrations, and osmolality, between the stool fluid and dialysate in vitro, the organic anion concentration was higher in the stool fluid than in the in vitro dialysate. This suggests that the difference between stool fluid and dialysate in vivo may be partly attributable to non-dialysable material in the stool fluid. This is unlikely to be the entire explanation, however, since sugars, which are fully dialysable, are present in considerably higher concentrations in stool fluid than in dialysate (table I and the figure). Furthermore, even the difference in organicanion concentration $(16 \%$ higher in thestool fluid than in the in vitro dialysate) would only have accounted for about half the observed difference between stool fluid and in vivo dialysate (table I) or could even have occurred by chance in this relatively small sample $(n=4)$.

The majority of specimens studied were analysed immediately; the remainder were deep-frozen within five minutes of being passed. Appreciable bacterial change could therefore only have occurred during the process of analysis. Table IV demonstrates the slow rate of bacterial action on faeces when kept at $4^{\circ} \mathrm{C}$ for 24 hours; all our studies were actually completed within six hours. Table $\mathrm{V}$ demonstrates that stool fluid prepared and analysed in our usual way shows no higher a concentration of organic anions or sugars than an aliquot of the same stool which was sterilized immediately with $10 \mathrm{ml} 10 \%$ formalin. None of these artefacts is sufficient to account for the marked difference in composition between stool fluid and dialysate in vivo.

Wrong et al (1965), demonstrated that dialysis bags came into rapid equilibrium with an aqueous solution of electrolytes in a situation in vitro, and also showed that the contents of dialysis bags introduced per rectum were of similar composition to those of bags which had traversed the whole of the gastrointestinal tract. With the methods at their disposal, however, they were unable to analyse stool fluid directly, and were therefore not in a position to prove that the fluid within the dialysis bags was in equilibrium with the surrounding stool fluid.

Wrong et al (1965) also showed that dialysis bags recovered from different parts of the same stool contained fluid of different composition, and attributed this to the heterogeneity of stool, assuming that each dialysis bag represented the composition of stool immediately adjacent to it. Table VIII confirms the variable composition of dialysates from the same stool and Table IX shows the results of analysing the stool fluid adjacent to each dialysis bag separately. As can be seen, the heterogeneity of stool composition cannot entirely account for the variability of dialysate composition.

Thus it seems that the difference in composition between stool fluid and stool dialysate cannot be accounted for by artefacts of our handling technique, or by continued fermentation of stool after passage. This still leaves the possibility that centrifuged stool supernatant differs in composition from the stool 'pellet'. Table VII demonstrates essentially the same composition in supernatant stool fluid and 'pellet' fluid, and, since dilution factors for the 'pellet' fluid were calculated assuming no sequestration of water within the 'pellet', suggests that (within the limits of experimental accuracy) all the stool water is present in a single compartment. This agrees with the findings of Findlay, Eastwood, and Mitchell (1973) who demonstrated, in adults with diarrhoeal stools, similar distribution of electrolytes between 'pellet' and supernatant fluid.

Our volunteers were both apparently normal, healthy individuals, and both produced in vivo stool dialysates of similar composition to those found by Wrong et al (1965) in their healthy volunteers. The relatively high concentrations of stool sugars in our two volunteers are noteworthy. Since only soft stools can be easily separated into supernatant and 'pellet' by centrifugation, it may be that our volunteers have a minor degree of sugar intolerance, although neither shows any clinical evidence of this.

It would seem unlikely that the difference noted between stool dialysate and stool fluid could be due to inadequate equilibration time in the large intestine, since Wrong et al (1965) have shown that dialysis bags can reach the large bowel within three hours of ingestion, and gut transit times in all our experiments were in excess of 24 hours. This would allow at least 21 hours for mixing and equilibration within the colon.

The higher sodium concentrations we found in the stool fluid compared with the dialysates in vivo are difficult to account for and we can offer no rational explanation for this.

The increase in sugar in stool fluid compared with the dialysate may be associated with bacterial breakdown of more complex carbohydrates such as celluloses and hemicelluloses. We have demonstrated (table IX) an increased concentration of stool fluid sugar following anaerobic incubation in vitro of stool at $37^{\circ} \mathrm{C}$. Similarly, fermentation of stool would account for increased organic anion formation, with a drop in $\mathrm{pH}$ and a rise in osmolality. The lower bicarbonate and higher ammonia figures may be partly explained by the increased acidity of the stool fluid compared with dialysate in vivo, since Down 
et al (1972) have shown in dialysates in vivo that these values are $\mathrm{pH}$ dependent, but part of the variation might be accounted for by bacterial action in the stool while still in the colon or rectum. It has been known for many years (Gamble, 1915, and table IX) that ammonia is generated by incubation of stool in vitro.

These results suggest that in our subjects stool dialysate in vivo may not be in equilibrium with the stool fluid surrounding it and may not represent a true dialysate of the extracellular component of faecal water. The rate of dialysis in the lower colon and rectum might be considerably delayed due to poor mixing; this would allow the accumulation of bacterial metabolites such as short-chain fatty acids and ammonia in the stool fluid. Down et al (1972) have provided evidence that an increase in the acidity of the medium will retard ammonia absorption.

We thank Professor O. Wrong for his advice and encouragement throughout this study, the Scottish Home and Health Department for financial support, and Mrs Joyce Paul for technical assistance.

\section{References}

Baron; D. N., and Economidis, J. (1963). Thin layer chromatography for aminoacids and sugars. J. clin. Path., 16, 484-486.

Cirillo, V. P. (1966). Symposium on bioelectrochemistry of microorganisms. I. Membrane potential and permeability. Bact. Rev., 30, 68-79.

Conway, E. J. (1957). Microdiffusion Analysis and Volumetric Error, 4th ed. Crosby, Lockwood, London.

Down, P. F., Agostini, L., Murison, J., and Wrong, O. M. (1972). The Inter-relationships of faecal ammonia, $\mathrm{pH}$ and bicarbonate: evidence of colonic absorption of ammonia by non-ionic diffusion. Clin. Sci., 43, 101-114.

Findlay, J. M., Eastwood, M. A., and Mitchell, W. D. (1973). The physical state of bile acids in the diarrhoeal stool of ileal dysfunction. Gut., 14, 319-323.

Gamble, J. L. (1915). The ammonia and urea content of infants' stool with a description of methods. Amer. J. Dis. Child., 9, 519-532.

Law, J. H. (1961). The lipids of E. coli. Bact. Proc., 129.

Schales, O., and Schales, S. S. (1941). Simple and accurate method for determination of chloride in biological fluids. J. biol. Chem., 140, 879-884.

Somogyi, M. (1952). Notes on sugar determination. J. biol. Chem., $195,19-23$.

Wrong, O., Metcalfe-Gibson, A., Morrison, R. B. I., Ng, S. T., and Howard, A. V. (1965). In vivo dialysis of faeces as a method of stool analysis. I. Technique and results in normal subjects. Clin. Sci., 28, 357-375.

Wrong, O., Morrison, R. B. I., and Hurst, P. E. (1961). A method of obtaining faecal fluid by in-vivo dialysis. Lancet (Lond.), 1 , 1208-1209.

Van Slyke, D. D., and Neill, J. M. (1924). The determination of gases in blood and other solutions by vacuum extraction and manometric measurement I. J. biol. Chem., 61, 523-573.

Van Slyke, D. D., and Palmer, W. W. (1920). Studies of acidosis XVI. The titration of organic acids in urine. J. biol. Chem., 41, 567-585. 